Cuadernos de Gobierno y Administración Pública ISSN: e-2341-4839

http://dx.doi.org/10.5209/CGAP.60611

\title{
El proceso de traspaso de la administración de justicia como instrumento de análisis de las dinámicas del Estado Autonómico
}

\author{
Eliseo López Sánchez*, Daniel Casal Oubiña**
}

Recibido: 07/05/2018 / Aceptado: 31/05/2018

Resumen. El artículo analiza los procesos de traspaso de competencias en materia de administración judicial a las Comunidades Autónomas. Aportando una visión sobre cómo se ha producido el proceso de construcción del actual Estado autonómico y nos permite comprender un importante elemento del funcionamiento de la administración judicial, elemento clave para el buen funcionamiento del poder judicial, un poder del Estado poco estudiado desde la ciencia política española. Además, el traspaso de esta competencia nos permite ejemplificar este tipo de procesos, que tampoco han merecido mucha atención, teniendo en cuenta que estos procesos pueden condicionar el posterior ejercicio de la competencia, y su comprensión nos aporta elementos clave para entender el funcionamiento real del Estado autonómico.

Palabras clave: Descentralización, poder judicial, administración de justicia, comunidades autónomas, administración judicial.

\section{The process of transferring the administration of justice as an instrument for analyzing the dynamics of the Autonomous State}

Abstract. The article analyzes the processes of transfer of competences in matters of judicial
administration to the Autonomous Communities. Providing a vision on how the process of construction
of the current autonomous state has taken place and allows us to understand an important element of the
operation of the judicial administration, a key element for the proper functioning of the judiciary, a state
power little studied from political science Spanish. In addition, the transfer of this competence allows
us to exemplify this type of process, which has not received much attention either, bearing in mind
that these processes can condition the subsequent exercise of the competence, and its understanding
provides us with key elements to understand the real functioning of the Autonomous state. Keywords: Decentralization, judicial power, administration of justice, autonomous communities, judicial administration.

Sumario. 1. Introducción. 2. Bases teóricas. 2.1. El Poder Judicial y la Ciencia Política. 2.2. El Neoinstitucionalismo histórico como marco teórico de referencia. 2.3. La administración de justicia en España como marco jurídico de referencia. 3. Diseño de la investigación. 3.1. Preguntas principales y secundarias. 3.2. Objetivos primarios y secundarios. 3.3. Hipótesis. 3.4. Elementos claves. 4. Resultados. El análisis del traspaso. 4.1. Traspaso de personal. 4.2. Traspaso de bienes materiales. 4.3. Negociación de la competencia posterior al traspaso. 5. Conclusiones. Documentos. Bibliografía.

Cómo citar: López Sánchez, E., Casal Oubiña, D., «El proceso de traspaso de la administración de justicia como instrumento de análisis de las dinámicas del Estado Autonómico», en Cuadernos de Gobierno y Administración Pública 5-1, 67-89.

* Universidad Complutense de Madrid

** EAE Business School. Universidad Rey Juan Carlos 


\section{Introducción}

Comprender cualquier proceso de traspaso de competencias permite tener herramientas para analizar cómo se ha articulado realmente el Estado autonómico. El proceso de traspaso de la administración judicial es uno de los mejores ejemplos de construcción del Estado autonómico, pero más por lo que tiene de caso extremo que de típico.

La mayoría de los artículos académicos sobre la administración de justicia en España son de tipo jurídico y tienden por tanto a analizar el sistema desde el apriorismo de la perfección del mismo, sin tener en cuenta elementos clave como las relaciones informales entre operadores jurídicos y empleados públicos, los pactos políticos o un análisis de las relaciones de poder entre actores. En este sentido, y teniendo en cuenta un análisis también jurídico, la presente investigación viene a cubrir el vacío existente en este campo de estudios desde la Ciencia Política y de la Administración.

En la actualidad tienen traspasada la administración judicial el País Vasco, Cataluña, Galicia, Andalucía, Navarra, Comunidad Valenciana, Canarias, Madrid, Asturias, Cantabria, Aragón, Extremadura, La Rioja y Castilla y León. El resto de las CC.AA. se encuentran en diferentes fases de negociación, desde el acuerdo a punto de firmarse como Murcia, hasta un avance lento en Castilla y León, pasando por Baleares, que está calculando el impacto de las rebajas del sueldo del personal en los costes del traspaso.

Este artículo comienza tratando de forma descriptiva algunos elementos clave necesarios para la comprensión de la administración de justicia, y continúa tratando los elementos más significativos de los traspasos de la competencia, pero no como procesos de traspaso, sino analizando estos elementos como ejemplo de la complejidad de la competencia y las peculiaridades que tiene. Primero se expone el personal, en el contexto de la nueva Oficina Judicial, y del cálculo del coste efectivo para traspasarlo a las CC.AA. Segundo, se exponen los bienes materiales y los servicios auxiliares, con su particular cálculo del coste efectivo y de las consecuencias en las relaciones intergubernamentales que tiene. Tercero, se detalla de forma más sistemática cuáles son los marcos de relaciones entre las instituciones implicadas en la administración judicial. Por último, se realiza una presentación de los principales hallazgos seguida de una conclusión final orientada a la continuación de la investigación de este objeto de estudio con más tiempo y medios.

La investigación permite ilustrar cómo se financia una competencia, cuáles son las relaciones económicas y la autonomía de las Comunidades. El caso es también un ejemplo de relaciones intergubernamentales, formales, informales, bilaterales, horizontales y multilaterales.

El artículo se basa en una investigación breve sobre los procesos de traspaso de la competencia de administración judicial a las CC.AA. La investigación en cuestión acabó mostrando varias de las cuestiones citadas en el párrafo anterior de una forma directa o indirecta al aparecer fenómenos paradójicos y disfuncionales en varios aspectos de la competencia. No todas las causas de estos aspectos se pudieron investigar en profundidad y de forma sistemática, con un enfoque de políticas públicas, debido a que la investigación original estaba limitada en tiempo y medios, y dirigida tan solo a mostrar las experiencias en los traspasos desde el punto de vista autonómico. 
El objetivo fundamental del trabajo era determinar las similitudes y diferencias de los distintos procesos de traspaso, teniendo en cuenta que se habían producido en diferentes momentos, de cara a identificar las mejores experiencias. El resultado final fue más allá de las expectativas, pues las diferencias y sus causas nos mostraron las complejidades del funcionamiento del Estado autonómico, en donde se cruzan asimetrías, relaciones de partido, el papel de las administraciones, el tribunal constitucional o la financiación.

\subsection{Bases teóricas}

\subsection{El Poder Judicial y la Ciencia Política}

El estudio de la organización del Estado y cómo se define en cada modelo político la separación de sus poderes, es uno de los aspectos más estudiados en las Ciencias Sociales y Jurídicas. Desde el punto de vista jurídico existe una gran cantidad de estudios que abordan la cuestión y que van desde el diseño constitucional de la separación de poderes (Jellinek, 1910; Pérez Royo, 2016; García Morillo, 1998) hasta el análisis pormenorizado de la estructura así como del funcionamiento administrativo del poder legislativo (Santaolalla, 2013; Astarloa, 2016) ejecutivo (Cendón, 2004) y, desde la perspectiva que aquí nos interesa, judicial (Gimeno Sendra, 2010; Moreno Catena, 2002; Orero, 2010).

En relación al funcionamiento del poder judicial hay un gran número de investigaciones jurídicas que analizan su estructura general, así como el funcionamiento de los diferentes órdenes jurisdiccionales (Salgado, 2010; Gómez y Serrano, 2015; Risueño, 2012) el funcionamiento de la fiscalía (Dalmau, 1999) la policía judicial (Gimeno Sendra, 2010) y la oficina judicial, que incluye al personal al servicio de la administración de justicia (Buján, 2009; Morato, 2005; Carrillo, 2005; Ballesteros, 2007). Estos estudios ofrecen un indudable interés descriptivo puesto que definen exhaustivamente las normas y las estructuras formales que regulan el funcionamiento del poder judicial, sus diferentes órdenes y diversos órganos que colaboran en el ejercicio de este poder del Estado.

Sin embargo los estudios de tipo jurídico plantean dos importantes limitaciones, en primer lugar analizan las estructuras desde una perspectiva formal y descriptiva, con lo cual suelen explicar el funcionamiento de las diferentes instituciones y administraciones públicas desde una visión que tiende a la perfección porque, los estudios jurídicos, no suelen prestar atención a factores clave en el funcionamiento de las instituciones y en la actuación de los operadores políticos o administrativos que participan en ellas, como son: las relaciones de poder, las relaciones informales, la politización de las mismas o incluso la perspectiva de recursos humanos, materiales y económicos con los que tienden a desarrollar su función.

La Ciencia Política y de la Administración Pública permite superar estas limitaciones, porque sin renunciar al valiosísimo análisis jurídico existente, incorpora elementos cruciales para entender el funcionamiento del poder judicial, en este caso, como las relaciones políticas, interadministrativas, informales y el análisis de la cultura organizacional y de los recursos humanos.

En este sentido la investigación vendría a completar un vacío existente en la propia Ciencia Política que rara vez se ha ocupado de estudiar el poder judicial, por 
considerarlo un "territorio de juristas" y a completar los estudios jurídicos existentes en la materia mediante la introducción de nuevas dimensiones que combinen el análisis formal con parámetros. Para ello se ha tomado como referencia teórica el Neoinstitucionalismo Histórico.

\subsection{El Neoinstitucionalismo histórico}

El neoinstitucionalismo histórico comparte con las corrientes tradicionales del institucionalismo (Peters, 2003) la premisa básica de intentar explicar el funcionamiento de las sociedades a partir del análisis de las funciones y efectividad de sus instituciones formales. Las distintas versiones del institucionalismo parten de que cada sistema social tiene una serie de funciones que tiene que cumplir, para las cuales se dota a sí mismo de una serie de instituciones específicas cuya finalidad es regular el comportamiento de los individuos.

De este modo las corrientes economicistas del neoinstitucionalismo analizan las relaciones económicas como el resultado de la interacción de diversas instituciones económicas (Samuels, 1995) que determinan el comportamiento de los individuos en el mercado, por su parte el institucionalismo jurídico considera que son las normas jurídicas agrupadas en Códigos y cuya efectividad va ligada a las sanciones en caso de incumplimiento las que condicionan las relaciones públicas y privadas entre los particulares "un conjunto de normas coactivas" es cómo define Kelsen (1934) al sistema jurídico y su capacidad para determinar el comportamiento de las personas. Por otro lado, el institucionalismo racionalista se centra en los agentes y en cómo las instituciones actúan como instrumentos de catalización de sus necesidades (Tsebelis, 1990) mientras que los institucionalistas culturalistas las instituciones actúan no como elemento de contención de sus anhelos sino como moldeador de las expectativas y deseos de los individuos (March y Olsen, 2010:15).

El neoinstitucionalismo histórico, por su parte, surge a partir de las teorías políticas del estructural-funcionalismo, entre 1960 y 1975. Según Hall y Taylor (1993) esta dimensión analítica se caracteriza porque asocia el diseño de las instituciones con la producción de normas formas e informales que actúan como mecanismo de socialización, formación e información para los actores políticos que operan en el marco de las mismas. Se trata, por lo tanto, de un método de análisis que es considerado como un instrumento teórico extraordinariamente pertinente para explicar, tanto la fenomenología política, como las relaciones estructura agente a partir de una perspectiva diacrónica (Bedoya, 2009:35).

En el neoinstitucionalismo histórico, también se asume la premisa de que son las instituciones las que determinan el comportamiento de los individuos en las sociedades, sin embargo, pone el énfasis en tres dimensiones: la path dependency, el proceso de producción de normas formales e informales y el rol de los actores.

La primera de estas dimensiones parte de la idea de que tanto cuando se constituye una institución, como cuando ésta comienza a desarrollar su actividad, genera una serie de normas, formales e informales con el objetivo de desarrollar una influencia prolongada, path dependency, y definida sobre el presente y el futuro de los actores políticos (Peters, 2003: 103). Por tanto, para el neoinstitucionalismo histórico las normas no solo determinan la conducta, sino que son un instrumento de socialización e información de los actores que operan en el sistema (North, 
1991; Ostrom, 2000) puesto que las normas además de definir las reglas del juego, sobre todo, son las que ofrecen a los actores las alternativas sobre las cuales van a tomar sus decisiones.

En este sentido es imprescindible, también, considerar el factor del "particularismo" que rodea cualquier decisión que adopta un operador político o institucional y cómo se moldea por la influencia que ejercen las estructuras y normas definidas por las instituciones. Por ello, frente a posturas que justifican la adopción de las decisiones públicas en el marco de una elección meramente racional dictada por los condicionantes exógenos (Boudon, 2009: 183), así como a frente quienes consideran que las políticas se implementan a partir del mandato de una norma jurídica, es necesario comprender que, sobre todo, las decisiones públicas se determinan por actores que cuentan con sus propias preferencias e intereses particulares (Lenski, 2013: 52) que pueden estar más o menos moldeados por la experiencia y el transcurso del tiempo (Stone, 2006: 3).

Por lo tanto, es un detalle crucial comprender tanto el diseño institucional, como las normas formales e informales que se derivan de él, porque van a definir las reglas del juego en el que se van a desenvolver los actores que operan en el marco de las organizaciones públicas Puesto que de las reglas y normas formales e informales se deriva la información que reciben finalmente los actores que, aunque cuentan con cierto margen de discrecionalidad, toman sus decisiones en base a los conocimientos que tienen.

\subsection{La administración de justicia en España como marco jurídico de referencia}

La Constitución Española de 1978 (CE) considera al Poder Judicial, siguiendo la tradicional separación de poderes, como uno de los 3 poderes del Estado (artículo $117 \mathrm{CE}$ ) y por lo tanto emana de los ciudadanos siguiendo el principio de soberanía popular reconocido en el artículo 1.2 de la CE.

El ejercicio del Poder Judicial en España se manifiesta en primer lugar como un derecho fundamental (artículo $24 \mathrm{CE}$ ) de los ciudadanos a acceder a la tutela de los jueces y tribunales para dirimir sus conflictos privados y para responder de las ofensas causadas a la sociedad y al conjunto del ordenamiento jurídico y político. Para su ejercicio la $\mathrm{CE}$ enumera aspectos claves que integran el contenido esencial de este derecho como por ejemplo la asistencia letrada, la imparcialidad del juez, la presunción de inocencia la función social de las penas privativas de libertad y las sanciones (artículo $25 \mathrm{CE}$ ) o la prohibición de los tribunales de honor (artículo $26 \mathrm{CE}$ ). Para poder realizar sus funciones el Poder Judicial necesita un aparato administrativo que comprende desde los empleados públicos que gestionan el procedimiento y lo impulsan administrativamente con todo tipo de actos (notificaciones, comunicaciones, etc.) hasta determinadas figuras que son necesarias para complementar la tarea de jueces y tribunales, como es el caso de los expertos forenses o incluso la policía judicial que participan en las investigaciones de los hechos investigados.

El aparato administrativo que apoya e impulsa la tarea del poder judicial es escasamente regulado en la Constitución y el legislador ha optado por encomendar su gestión corriente a diversos departamentos del poder ejecutivo (Ministerio de Justicia, Ministerio del Interior, Ministerio de Hacienda, etc.) generando una situación que si bien desde el punto de vista legal no presenta problemas e incluso se encuentra 
en sistemas jurídicos comparados, desde una perspectiva de tipo administrativo puede suscitar dificultades debido a que la dependencia jerárquica puede ser un factor importante de distorsión debido a que el titular del órgano jurisdiccional (juez o magistrado) no tiene capacidad efectiva sobre el personal que tiene a su cargo desde un punto de vista laboral.

Esta situación se ve complicada desde el punto de vista del proceso de descentralización del poder que se ha realizado en España desde la Constitución de 1978 que define en su artículo 2 y su Título VIII una estructura territorial de corte federal. De modo que si bien la justicia se ejerce mediante un poder judicial único en todo el Estado y su administración es competencia exclusiva estatal (artículo 149.1. $5^{\mathrm{a}}$ ) la gestión de ésta competencia se ha ido transfiriendo de forma paulatina a las CCAA. Por lo tanto, la Constitución articula un sistema extremadamente complejo: define un poder del Estado, emanado del pueblo, que configura un derecho fundamental y que es operado por el denominado de forma genérica "poder judicial" que integra por un lado a jueces y magistrados de carrera que se ven apoyados por un conjunto de recursos materiales y personales que dependen del poder ejecutivo central y cuya gestión se está transfiriendo a cada una de las Comunidades Autónomas que integran España.

\section{Diseño de la investigación}

A partir de la justificación y de la revisión de la literatura que se ha realizado con anterioridad, es imprescindible avanzar en el planteamiento de un diseño de investigación, cuyo objetivo principal es verificar la hipótesis central de este trabajo que es determinar que el traspaso de competencias en materia de administración judicial es un proceso que sirve para explicar las dinámicas intergubernamentales del Estado Autonómico.

\subsection{Pregunta principal y preguntas secundarias de investigación}

- Pregunta Principal:

- ¿Sirven los procesos de traspasos competenciales para explicar el funcionamiento efectivo del Estado de las CC. AA?

- Preguntas Secundarias:

- ¿Cómo es el Estado de las CC. AA? ¿Cómo es la distribución competencial?

- ¿Cómo funciona la Administración Judicial en España? ¿Cómo es la distribución competencial en materia de Administración Judicial?

- ¿Cómo son los traspasos de competencias? ¿Cómo ha sido el traspaso en materia de justicia?

\subsection{Hipótesis}

La hipótesis de la que parte esta investigación es que el proceso de traspaso de competencias en materia de administración de justicia a cada Comunidad Autónoma explica las diferencias posteriores que pueden tener a la hora de ejercer la competencia, siendo esto un ejemplo del funcionamiento real del Estado autonómico. 


\subsection{Elementos claves}

En primer lugar, es imprescindible acotar el término "administración judicial", ya que no es el comúnmente utilizado ni por los responsables del ámbito del Derecho, ni por los medios de comunicación. En estos ámbitos se habla comúnmente de "la justicia" tanto para referirse al poder judicial como para referirse a la "administración judicial". Sin embargo, parece más exacto hablar de administración judicial para referirse a la organización burocrática que desarrolla las acciones del poder judicial, porque tiene más precisión semántica.

Básicamente lo que el Estado traspasa en materia de administración judicial son funciones y servicios de apoyo respecto al poder judicial, es lo que el Tribunal Constitucional ha definido como "administración de la administración judicial". Esto se refiere al pago del personal, la construcción de nuevas sedes judiciales, los gastos corrientes, el suministro del material de oficina a los juzgados, los programas informáticos, el pago de la asistencia legal gratuita y los peritos, la limpieza y el mantenimiento de las sedes.

Todas estas funciones y servicios apoyan a un conjunto de órganos judiciales cuyo ámbito territorial de actuación sea igual o inferior al autonómico, que son parte del poder judicial y que no se traspasan. Los órganos judiciales, las unidades de las que se compone el poder judicial, son orgánicamente independientes tanto de las instituciones autonómicas como de los poderes legislativo y ejecutivo del Estado central. Estos órganos incluyen a los de carácter unipersonal, los juzgados, y a los de carácter colegiado, audiencias y tribunales superiores. La distribución territorial de estos órganos es lo que se denomina la planta judicial, en la que se establece la cantidad de órganos y la demarcación de cada uno.

Los traspasos, por tanto, afectarían a las funciones y servicios que apoyan a los órganos judiciales de ámbito autonómico o inferior. El Estado central es el que decide cuál es la planta judicial y la tiene que revisar por Ley cada cinco años. No obstante, las CC.AA. con competencias en materia de administración judicial tienen la potestad de enviar un informe al Ministerio de Justicia para solicitar la creación de los órganos judiciales que consideran necesarios en su territorio. También emite un informe el Consejo General del Poder Judicial, CGPJ que es el gobierno de los jueces.

Hay que señalar que también hay un gobierno del Poder Judicial, el Consejo General del Poder Judicial, que se encarga de jueces y magistrados: reclutamiento, regula la carrera profesional, asigna los puestos por concurso, establece las posibles sanciones y se encarga de la formación continua. Como consecuencia del "Pacto de Estado para la Reforma de la Justicia" (en adelante, "Pacto de la Justicia") que firmaron en 2001 el Gobierno central, el PP y el PSOE, el Ministerio de Justicia llevó a cabo una profunda reestructuración de la planta judicial adicional a la revisión quinquenal, con el objetivo de adaptarla a una implantación de la nueva Oficina Judicial, que todavía no ha finalizado. En 2012, se produjo la última revisión de la planta judicial.

El hecho de que cada cinco años pueda variar la planta, y por tanto el número de órganos, han generado un cierto entorno de incertidumbre e indefinición en los traspasos de esta competencia a las CC.AA., ya que las funciones y servicios cambian con la planta judicial. A esto se añade que el traspaso se hace sobre los elementos de un poder ajeno, el judicial, que no se traspasa y no participa en el proceso de traspaso, y cuya estructura, organización y sobre todo intereses, es independiente. 
Tabla 1. Planta territorial de los órganos judiciales en España.

\begin{tabular}{|c|c|}
\hline Demarcación & Órganos que actúan \\
\hline Municipio & Juzgado de Paz \\
\hline $\begin{array}{l}\text { Partido Judicial: demarcación } \\
\text { de varios municipios dentro de } \\
\text { una misma provincia }\end{array}$ & $\begin{array}{l}\text { Juzgado de Instrucción (Penal). } \\
\text { Juzgado de Primera Instancia (Civil) } \\
\text { Juzgado especializado sobre Violencia de Género (Penal). }\end{array}$ \\
\hline Provincia & $\begin{array}{l}\text { Juzgados especializados funcionalmente: } \\
\text { - Juzgados de lo Contencioso-Administrativo. } \\
\text { - Juzgado de lo Penal. } \\
\text { - Juzgado de lo Mercantil. } \\
\text { - Juzgado de lo Social. } \\
\text { - Juzgados de Menores. } \\
\text { - Juzgados de Vigilancia Penitenciaria. } \\
\text { Audiencias Provinciales (Penal y Civil) }\end{array}$ \\
\hline Comunidad Autónoma & $\begin{array}{l}\text { Tribunal Superior de Justicia: } \\
\text { - Sala de lo Civil-Penal. } \\
\text { - Sala de lo Contencioso-Administrativo. } \\
\text { - Sala de lo Social. }\end{array}$ \\
\hline Estado & $\begin{array}{l}\text { Audiencia Nacional: } \\
\text { - Juzgados Centrales de Instrucción (Penal) } \\
\text { - Juzgados Centrales de lo Penal. } \\
\text { - Juzgado Central de lo Contencioso-Administrativo. } \\
\text { - Juzgado Central de Vigilancia Penitenciaria. } \\
\text { - Juzgado Central de Menores. } \\
\text { - Sala de lo Penal. } \\
\text { - Sala de lo Contencioso-Administrativo. } \\
\text { - Sala de lo Social. } \\
\text { Tribunal Supremo: } \\
\text { - Sala de lo Civil. } \\
\text { - Sala de lo Penal. } \\
\text { - Sala de lo Contencioso-Administrativo. } \\
\text { - Sala de lo Social. } \\
\text { - Sala de lo Militar. }\end{array}$ \\
\hline
\end{tabular}

Fuente: Elaboración propia.

Además, desde 2001 se añade a ese entorno una mayor incertidumbre por la lenta implantación de la nueva Oficina Judicial, un nuevo modelo de gestión administrativa que desliga las funciones y servicios de la administración judicial de cada órgano judicial, como existía hasta ahora, concentrando funciones, servicios y bienes materiales en unidades administrativas que apoyan a varios órganos judiciales a la vez. En principio, las CC.AA. que hayan recibido la competencia antes de 2008, han tenido que desarrollar e implantar su propio modelo de nueva Oficina Judicial, con las bases anteriores, y los últimos traspasos, a Cantabria, Aragón, Extremadura, La Rioja y Castilla y León, ya han recibido la competencia con el modelo del Estado central. No obstante, al estar muy reciente la implantación, no se conocen bien sus resultados e impactos sobre las funciones y servicios que se traspasan. Estos elementos generan 
incertidumbre porque una vez traspasada la competencia, esta se puede ver sujeta a importantes cambios o a conflictos con el poder judicial que no pueden ser controlados o contemplados en el traspaso.

\section{Resultados. El Análisis del traspaso}

Esta competencia se comenzó a traspasar a partir de una Sentencia del TC que partió de dividir la "administración judicial" de la "administración de la administración judicial", siendo esta última parte traspasable a las CC.AA., ya que la "administración judicial" como tal es una competencia exclusiva del Estado central, según el artículo 149 de la Constitución. A partir de esta sentencia se comenzaron a producir los primeros traspasos, al País Vasco y Cataluña, a fines de la década de los 80, en un proceso que dura hasta la actualidad.

El proceso típico de traspaso de esta competencia se inicia con la negociación en la Comisión Mixta de Transferencias que se constituye entre el Estado y cada Comunidad Autónoma. En esta Comisión se crean cuatro grupos de trabajo: Personal, Coste Efectivo y Financiación, Obras y Patrimonio e Informática.

Cada grupo de trabajo tiene que llegar a un acuerdo independientemente, que se integra con el resto en un acuerdo común. Este acuerdo sirve de base para redactar los Reales Decretos mediante los que el Estado ejecuta el traspaso. En esta competencia hay dos tipos de Reales Decretos, en uno se traspasa el personal y en otro los bienes materiales y las funciones auxiliares. Puede que haya un acuerdo global, a nivel político, y que queden pendientes acuerdos en determinados aspectos de un grupo de trabajo concreto. En estos casos, suelen existir más Reales Decretos que aplican lo acordado. En cualquier caso, vamos a estudiar con más detenimiento estos dos grandes tipos de traspaso que componen la competencia, ya que en estos traspasos está el origen de disfunciones que tiene la administración judicial española.

\subsection{El Traspaso del personal}

El traspaso del personal es bastante simétrico al conjunto de las CC.AA., puesto que se traspasan los puestos de trabajo adscritos a los órganos judiciales pertinentes, o a las oficinas actualmente, radicadas en el territorio autonómico. El elemento clave del proceso de negociación que se abre para efectuar este traspaso, en realidad para cualquier traspaso de cualquier competencia en el Estado autonómico es el coste efectivo.

El coste efectivo es el cálculo de lo que se supone que le cuesta al Estado central prestar esa competencia de forma ordinaria en ese territorio anualmente, esto es, lo que se gasta el Estado central sin considerar las inversiones reales, como las destinadas a obras extraordinarias, instalación de programas informáticos especiales o en material informático extraordinario vinculado a la implantación de la nueva Oficina Judicial, por ejemplo. Esta valoración se supone que es lo que debería costar anualmente a cada Comunidad Autónoma ejercer la competencia que le traspasa el Estado. El Estado central, a través de los Reales Decretos de Traspaso, queda obligado a transferir anualmente, a cada Comunidad Autónoma que ejerce la competencia, fondos por una cantidad equivalente al coste efectivo. Esta cantidad se actualiza con el 
IPC y, en su caso, se aprovechas los cambios en el sistema de financiación autonómico, para cubrir el gasto real que tienen las CC.AA. en esta materia.

Hay que destacar que este sistema de cálculo sobre el coste de las transferencias es de suma cero. El sistema de coste efectivo supone, de forma implícita, que el gasto estatal en una competencia es divisible territorialmente y la suma de cada una de las partes nos daría el coste total. En realidad, esto es falso. Los costes indirectos que tiene el Estado central no son imputables territorialmente en su totalidad, como por ejemplo los servicios comunes, que, al estar centralizados, son más reducidos. Al descentralizarse la competencia se multiplican los centros de gasto, como por ejemplo los departamentos prestadores de servicios internos de la administración, y se reducen las economías de escala de prestación de servicios externos, todo lo cual aumenta el coste respecto a la prestación centralizada.

Lo anterior implica que la mayoría de las competencias, no sólo la de administración judicial, se traspasaron con unos cálculos de coste inferiores a los reales y se han requerido financiaciones extraordinarias continuamente, sobre todo en el caso de los primeros traspasos que se realizaron. Estas demandas crecientes llevan a reivindicaciones económicas continuas de los gobiernos autonómicos, a reclamaciones de inversiones del Estado central. En la administración judicial la financiación extraordinaria ha provenido fundamentalmente de inversiones en bienes materiales, particularmente en obras extraordinarias. No obstante, hay que señalar que los frecuentes cambios en los sistemas de financiación autonómica tratan de corregir estas desviaciones en todas las competencias traspasadas, y que la experiencia acumulada en los traspasos hace que los cálculos sean cada vez más precisos.

En cualquier caso, las entrevistas realizadas para la investigación muestran que incluso existieron diferencias entre los gastos efectuados por las CC.AA. el primer año y lo presupuestado en los documentos de traspaso. En Canarias el técnico Joaquín García Gómez señaló que el coste real fue más de un millón de euros superior al coste efectivo que habían acordado en el primer año de ejercicio, 1997. Por su parte, Patricia Montagud, directora general de administración de Justicia de la Comunidad Valenciana en 2006 estimaba que lo que el Estado transfirió como coste efectivo fue inferior en más de un $40 \%$ al gasto real que tuvieron en administración judicial.

Hay que considerar que un desfase muy amplio entre el coste efectivo calculado y el coste real del ejercicio de la competencia se repite anualmente, por lo que se convierte en un problema serio para la financiación de la Comunidad, al menos hasta la siguiente revisión del sistema de financiación autonómica. También hay que señalar que los técnicos que participan en el proceso de traspaso y en la posterior gestión de las competencias, tanto del Estado central como de las CC.AA., son conscientes de esta situación, y de que el cálculo del coste efectivo es una ficción. Por ello, a la hora de negociar, unos y otros intentan "arrimar la ascua a su sardina" imputando costes indirectos de más respecto al personal o incrementando la financiación extraordinaria. Al final, conseguir una valoración mejor o peor depende de tres elementos clave: Impulso Político, Momento Histórico y Habilidad de los Técnicos de ambas partes.

A partir de aquí, tenemos que la mayor parte del coste efectivo de la administración judicial es un coste directo, el del personal que se traspasa. El Estado central y la Comunidad Autónoma calculan en la Comisión Mixta de Transferencias el coste de lo que el Ministerio de Justicia se gastó en el ejercicio anterior en cada puesto de 
Tabla 2. Criterios para mejorar la valoración.

\begin{tabular}{|l|l|}
\hline \multicolumn{1}{|c|}{ Criterio } & \multicolumn{1}{c|}{ Características } \\
\hline Impulso Político & $\begin{array}{l}\text { Puede provenir de una definición del interés que tiene la competencia } \\
\text { para la Comunidad Autónoma, o del interés del Estado en traspasarlo, } \\
\text { como sucede en la actualidad. Aquí interviene, para que este impulso } \\
\text { sea más efectivo, la coincidencia de color político entre el gobierno de } \\
\text { la Comunidad y el del Estado central, elemento que suele impulsar el } \\
\text { traspaso. }\end{array}$ \\
\hline Momento Histórico & $\begin{array}{l}\text { En el que se realiza el traspaso, ya que no son iguales las circunstancias ni } \\
\text { la experiencia a la hora de realizar los cálculos a finales de la década de los } \\
80 \text { y la de los 90, que a finales de la década pasada o en la actualidad. }\end{array}$ \\
\hline $\begin{array}{l}\text { Habilidad de los } \\
\text { Técnicos }\end{array}$ & $\begin{array}{l}\text { Para convencer a la otra parte de que lo calculado se ajusta a la realidad. } \\
\text { En este sentido, ha solido tener ventaja el Estado central, ya que tienen una } \\
\text { experiencia previa en traspasar la administración judicial, que los técnicos } \\
\text { de la Comunidad no tienen. }\end{array}$ \\
\hline
\end{tabular}

Fuente: Elaboración propia.

trabajo que se traspasa, que fundamentalmente es el personal que trabaja para los órganos judiciales de la Comunidad. Para ello la Comunidad Autónoma y el Estado central utilizan la Relación de Puestos de Trabajo (RPT) del Ministerio de Justicia y contabilizan los gastos de cada uno de los puestos de trabajo que se van a traspasar. Estos gastos son fundamentalmente el salario y los complementos retributivos de cada puesto de trabajo, ocupado o vacante. En este sentido hay que considerar que puede haber algunos puestos de trabajo que no están ocupados por ningún empleado en el momento del traspaso, pero que constan en la RPT y que el Estado también debe traspasar a las CC.AA.

Hemos de señalar que se han producido algunos errores entre el número real de personal traspasado y el que consta en los Reales Decretos en los casos de la Comunidad Valenciana, Navarra y, particularmente Andalucía: "Se observó una diferencia importante en el número de funcionarios, pues personas que prestaban sus servicios en la Administración de Justicia no aparecían entre los traspasados. En pesetas, esos funcionarios suponen una diferencia de algo más de 900 millones de pesetas".

En resumen, respecto al personal que se traspasa pueden producirse importantes diferencias entre unas Comunidades y otras, a pesar de que el proceso sea formalmente semejante, según se haya hecho el traspaso en un momento u otro, ya que los errores mayores se han detectado en los años 90.

\subsection{El Traspaso de los bienes materiales}

Si el traspaso del personal es simétrico, en relación con los bienes materiales y funciones auxiliares existen diferencias sutiles entre los traspasos del Estado a cada una de las CC.AA., que acaban teniendo una importante trascendencia. No obstante, hay también un patrón común de materias que se traspasan como se puede apreciar en la Tabla 3. 
Tabla 3. Patrón común de materias que se traspasan.

\begin{tabular}{|l|l|}
\hline \multicolumn{1}{|c|}{ Materia Objeto de Traspaso } & \multicolumn{1}{c|}{ Características } \\
\hline $\begin{array}{l}\text { La adquisición, y en su caso construcción, } \\
\text { de medios materiales muebles e } \\
\text { inmuebles (sedes judiciales) de los } \\
\text { órganos judiciales y de las Oficinas } \\
\text { Judiciales. }\end{array}$ & $\begin{array}{l}\text { Esto incluye los edificios, las inversiones en } \\
\text { todo el material de ofimática, mobiliario, los } \\
\text { programas informáticos, etc., así como los gastos } \\
\text { corrientes de los mismos, como electricidad, agua, } \\
\text { mantenimiento, etc. }\end{array}$ \\
\hline Función de Planificación & $\begin{array}{l}\text { De los bienes materiales muebles e inmuebles que } \\
\text { serán necesarios en un futuro para prestar el servicio. }\end{array}$ \\
\hline $\begin{array}{l}\text { Instalación y Puesta en funcionamiento } \\
\text { de nuevos Juzgados con sus recursos } \\
\text { materiales y económicos asociados, } \\
\text { incluidos también los gastos corrientes }\end{array}$ & $\begin{array}{l}\text { Esto incluye la organización e intendencia necesaria } \\
\text { para que pueda comenzar a funcionar un nuevo } \\
\text { juzgado. }\end{array}$ \\
\hline $\begin{array}{l}\text { La provisión de medios materiales y } \\
\text { económicos a los institutos de medicina } \\
\text { legal }\end{array}$ & Hay uno por provincia. \\
\hline Funciones Auxiliares & $\begin{array}{l}\text { Subvenciones para el turno de oficio, diligencias y } \\
\text { tramitaciones procesales y las dietas de los empleados. }\end{array}$ \\
\hline
\end{tabular}

Fuente: Elaboración propia.

Sobre todos estos bienes materiales y servicios se hace una valoración del coste efectivo, semejante al que hemos resumido en el apartado anterior: se negocia una aproximación de lo que el Estado central se supone que gasta en la Comunidad Autónoma correspondiente, más la suma de los costes indirectos. Para calcular este coste efectivo se utilizan los programas y partidas del Ministerio de Justicia en los Presupuestos Generales del Estado (PGE) del año anterior al de la negociación y se siguen varios pasos.

El coste efectivo de los bienes materiales y funciones auxiliares sería el resultado de la suma de la aplicación del módulo de valoración, específico para cada Comunidad Autónoma, a cada una de las partidas presupuestarias anteriores.

El problema para que esta valoración del coste efectivo se aproxime a la realidad es que la mayoría de las partidas presupuestarias del Ministerio de Justicia son globales y contemplan todo el territorio que en esos momentos gestiona el Estado. Por ello, es casi imposible calcular de manera precisa cuáles son los gastos que hace el Estado en un determinado territorio, ya que existen partidas presupuestarias que no están asignadas a órganos judiciales, ni Oficinas Judiciales concretas en la actualidad, que entrarían en la categoría de costes indirectos. Ejemplos de ellos, son el desarrollo de un programa informático para la administración de justicia, que se considera un bien material, o también los gastos de planificación de las necesidades futuras de bienes muebles e inmuebles. Las posibilidades de error en este terreno también han ido disminuyendo con el tiempo, ya que cuantos menos territorios gestiona el Estado, mayores aproximaciones pueden hacer las partes negociadoras de lo que se gasta en una Comunidad.

En cualquier caso, existe un margen de negociación del coste efectivo de los bienes materiales y funciones auxiliares, que es superior al del caso del personal. Según 
Tabla 4. Proceso de cálculo del coste efectivo.

\begin{tabular}{|c|c|}
\hline Paso & Características \\
\hline $\begin{array}{l}\text { El Estado central y la Comunidad } \\
\text { Autónoma negocian un porcentaje } \\
\text { 1lamado "módulo de valoración" }\end{array}$ & $\begin{array}{l}\text { Se basa: } \\
\text { - Principalmente, en la población de la Comunidad } \\
\text { Autónoma respecto al total de la población del } \\
\text { territorio que sigue siendo gestionado por el Estado } \\
\text { en ese momento. } \\
\text { - Secundariamente, en factores específicos que la } \\
\text { Comunidad Autónoma alega para que el Estado } \\
\text { central considere y pondere. Como factores } \\
\text { específicos se utilizan particularidades geográficas, } \\
\text { socioeconómicas o extraordinarias. }\end{array}$ \\
\hline $\begin{array}{l}\text { Este módulo de valoración se aplica } \\
\text { a cada partida presupuestaria de } \\
\text { gasto de los PGE que el Ministerio } \\
\text { de Justicia dispone para los bienes } \\
\text { materiales y funciones auxiliares } \\
\text { de la administración judicial en el } \\
\text { año anterior al que se produce la } \\
\text { negociación }\end{array}$ & $\begin{array}{l}\text { Respecto a: } \\
\text { - Gastos Corrientes (Capítulo II): por ejemplo, los gastos } \\
\text { de funcionamiento como agua, electricidad o teléfono, } \\
\text { de las sedes judiciales o el material de oficina. } \\
\text { - Subvenciones (Capítulo IV): por ejemplo los gastos } \\
\text { de asistencia letrada gratuita, los traductores y } \\
\text { otros trámites procesales vinculados a las funciones } \\
\text { auxiliares. }\end{array}$ \\
\hline
\end{tabular}

Fuente: Elaboración propia.

D. José García del Olmo, Subdirector General de Coordinación Territorial del Ministerio de Justicia en 2006, el Estado central transfería anualmente, dentro del coste efectivo, unos fondos específicos para construcción y reforma de sedes de órganos judiciales. Las CC.AA. no tienen que justificar en qué se gastan estos fondos y los reciben tanto si lo emplean en construcción y reforma como si lo hacen para otro fin. No obstante, la diferencia subjetiva de los módulos de valoración hace que no haya dos traspasos de bienes materiales vinculados a la administración judicial iguales. A este factor subjetivo, hay que añadir de otras particularidades que se produjeron en algunos de los primeros casos de traspaso, y que con el tiempo se han convertido en un agravio comparativo para las CC.AA. que han recibido la competencia más tarde.

En el caso de Cataluña, en el acuerdo final de 1990 consiguió no hacerse cargo de la creación de nuevos órganos judiciales, limitando el traspaso de bienes materiales. La particularidad está en que añadieron una frase al final del acuerdo que no se ha vuelto a repetir con el resto de CC.AA.

En la enumeración de las funciones y servicios traspasados en el Real Decreto 966/1990, Cataluña asume: "La adquisición y gestión de patrimonio mobiliario, inmobiliario y enseres para los órganos judiciales con sede en Cataluña, que no corresponda a la creación de nuevos órganos." La frase parece irrelevante, pero implica que Cataluña no asumió las competencias de construcción o adquisición de inmuebles para nuevos órganos judiciales, aunque en 1996 asumió la función de instalar y poner en funcionamiento los nuevos órganos judiciales que el Estado central creara en Cataluña. Hasta entonces, el Estado central también financiaba la puesta en funcionamiento de los nuevos órganos judiciales. También en ese año, a cambio del apoyo de Convergencia y Unió en el Congreso de los Diputados al Gobierno de José María Aznar, se llegó 
a un "Acuerdo complementario sobre módulos generales de valoración a aplicar a los órganos judiciales" en la Comisión Mixta de Transferencias, por el que se fijaron las cantidades por metro cuadrado de lo que iba a asumir del Estado por cada sede para cada nuevo órgano judicial que se creara. Hasta la fecha hoy, 2018, el detalle de estos módulos de valoración nunca ha sido publicado en ningún boletín oficial y el resto de CC.AA. no lo ha conocido hasta hace menos de 10 años.

La práctica catalana significa que se negocia edificio a edificio, con la base de los módulos de valoración acordados en 1996. Hasta 2006, Cataluña construyó o adquirió 13 nuevos inmuebles para nuevos órganos judiciales. En cada uno, el Estado central ha financiado de forma directa:

- Un porcentaje del coste de los inmuebles, que se transfiere a Cataluña una vez que se han construido.

- Otra cantidad para los gastos corrientes de los servicios que se van a prestar en los nuevos juzgados, que se integra y consolida en el coste efectivo: mantenimiento del edificio, limpieza, mobiliario, ofimática, electricidad, teléfono, correos, etc.

El resultado de esta financiación adicional ha sido que Cataluña ha conseguido del Estado central casi 25 millones de euros para la construcción de edificios e incrementó su coste efectivo en gastos corrientes en 9.4 millones de euros entre 1994 y 2006, más de un 50\% sobre el importe que le transfería el Estado por ese concepto en 1990.

Todos los expertos consultados coinciden en que la Generalidad de Cataluña ha conseguido una financiación del Estado central superior a la del resto de las CC.AA. para la construcción de inmuebles y para los gastos corrientes necesarios en su posterior funcionamiento, ya que el resto se tiene que conformar con financiarse estos gastos, aunque destine a los mismos los fondos específicos para construcción y reforma que les transfiere el Estado central, porque estos fondos son inferiores a los par-

Gráfico 1. Ampliaciones en Traspaso de Medios a la Generalidad de Cataluña (en miles de euros).

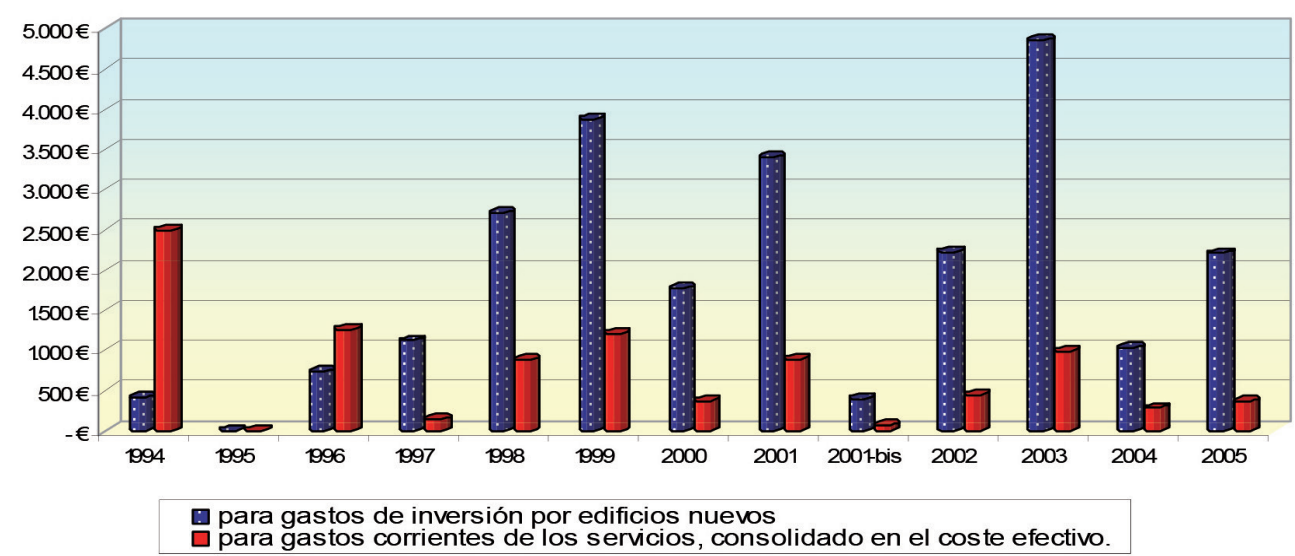

Fuente: Elaboración propia. 
ticulares y opacos módulos de valoración que tiene Cataluña. Debido a la ventaja que suponía este método para la parte autonómica, el Estado central no ha querido volver a utilizar esta práctica para los traspasos a otras CC.AA.

En compensación, la Generalidad de Cataluña financia la adquisición o reforma de los edificios para las sedes en las que se ubican los órganos judiciales cuyo personal y servicios auxiliares fueron traspasados antes de 1990 mediante los fondos específicos para construcción y reforma de edificios destinados a órganos judiciales. Según los responsables autonómicos entrevistados estos fondos han sido insuficientes para cubrir los gastos en todas las comunidades autónomas, por lo que la Generalidad de Cataluña ha tenido que dedicar importantes fondos a reformar edificios, informática y mobiliario.

Además de Cataluña, también han conseguido del Estado central financiaciones adicionales para inmuebles destinados a sedes de nuevos órganos judiciales otras comunidades de manera particular. A pesar de que los expertos consultados señalaron que no tiene unos beneficios tan elevados como Cataluña, Galicia consiguió financiación adicional del Estado para la construcción de inmuebles de nuevos órganos judiciales independientemente de los fondos específicos que recibe anualmente para inversiones en este concepto. Al mismo tiempo que firmaba el acuerdo inicial del traspaso de la administración judicial, en 1994, la Junta de Galicia firmó un "Acuerdo Complementario". Como consecuencia del mismo el Estado ha transferido a Galicia fondos para inversiones en nuevas sedes de órganos en cinco ocasiones, mediante sucesivos traspasos complementarios, que se caracterizan porque:

- Son transferencias sólo para la construcción de los edificios, y no incluyen la puesta en funcionamiento de los servicios.

- Los fondos se transfieren antes de que se construyan los edificios.

- Los traspasos no contemplan los gastos corrientes de los servicios de las nuevas sedes en los años sucesivos, por lo que estos gastos de asumirlos la Comunidad Autónoma.

Entre 1996 y 1999, Galicia recibió más de 12 millones de euros para gastos de inversión en nuevas sedes judiciales.

Gráfico 2. Gastos de inversión para nuevas sedes judiciales recibidos por Galicia.

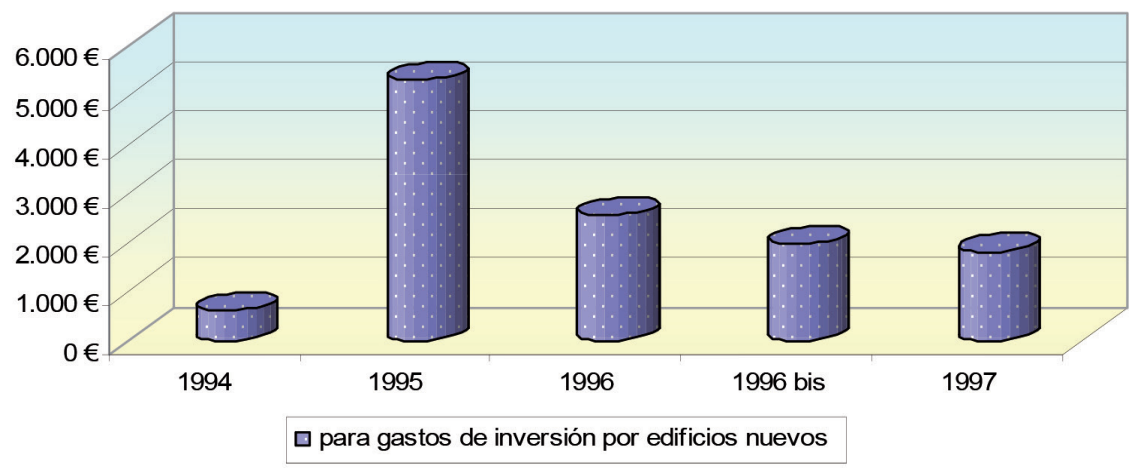

Fuente: Elaboración propia. 
Al igual que en el caso catalán, el Acuerdo Complementario no ha sido publicado ni se ha incluido en ningún Real Decreto de traspaso. Sin embargo, en cada Real Decreto de ampliación de los medios materiales a Galicia se han reflejado con detalle sus consecuencias.

Además de los casos gallego y catalán, existen otros dos casos de financiaciones adicionales y extraordinarias de edificios, en los que el Estado central solo cofinancia la obra y se desentiende de los gastos de instalación y puesta en funcionamiento de nuevos juzgados. En estos casos el Estado central concede ayudas para la construcción o reforma de inmuebles singulares, de gran tamaño, destinados a ser sede de numerosos órganos judiciales ya existentes. En estos casos, los Reales Decretos de traspaso inicial habían previsto la financiación de estos inmuebles singulares, porque se negoció al mismo tiempo que el traspaso inicial de la competencia. El inconveniente de esta práctica es que es discrecional, el Estado central puede reconocer la necesidad de un edificio singular o no.

En estos casos el Estado financiaría una parte de los gastos de reubicación de unos órganos judiciales, que ocupan inmuebles deteriorados, en el caso canario, o dispersos, en el madrileño. Los sitúa así en unas instalaciones adecuadas para la prestación del servicio al público y busca también agrupar los órganos judiciales, que supone un ahorro en los gastos corrientes al aplicarse economías de escala.

Hay que señalar que además de estos bienes inmuebles, el Estado central también traspasa todo el mobiliario y material de oficina, los vehículos, el hardware y el software informático. En los Reales Decretos de traspaso se incluye que el Estado y las CC.AA. deberían colaborar en la promoción de los bienes informáticos y en asegurar la compatibilidad de los programas con los del resto del territorio del Estado.

\subsection{Negociaciones de la competencia posteriores al traspaso}

Los expertos autonómicos entrevistados coincidieron en que la financiación estatal es insuficiente para cubrir los gastos reales posteriores al momento del traspaso. A los desfases y errores del coste efectivo en la negociación, hay que añadir, por un lado, que como consecuencia de la restructuración de la planta judicial se ha incre-

Tabla 5. Otros casos de financiación adicional y extraordinaria.

\begin{tabular}{|l|l|}
\hline \multicolumn{1}{|c|}{ Comunidad Autónoma } & \multicolumn{1}{c|}{ Características } \\
\hline Canarias & $\begin{array}{l}\text { El Estado central le traspasó dos partidas anuales, de 600.000 y } \\
720.000 \text { euros, para la realización de obras de reforma y ampliación } \\
\text { de un edificio singular en Las Palmas en 1996 y 1997, sede de la } \\
\text { Audiencia Provincial y de numerosos juzgados. }\end{array}$ \\
\hline Comunidad de Madrid & $\begin{array}{l}\text { El Estado central le transfirió 13 millones euros en cuatro anualidades } \\
\text { desde 2002 hasta 2006 para el "Campus de la Justicia”. Este es un } \\
\text { espacio en el que se reubicarán los juzgados especializados de Madrid, } \\
\text { la Audiencia Provincial y otros de competencia estatal como los } \\
\text { juzgados centrales y la Audiencia Nacional. }\end{array}$ \\
\hline
\end{tabular}

Fuente: Elaboración propia. 
mentado el número de órganos judiciales, circunstancia que pudo no tenerse en cuenta en el momento del traspaso. Por otro lado, los gastos del Estado central han estado históricamente por debajo de las necesidades reales de bienes materiales.

El resultado final es que una vez traspasada la competencia, los dirigentes autonómicos tienen que considerar una elevada inversión en bienes inmuebles. Todas las CC.AA. que han recibido la competencia han tenido que acometer profundas reformas o nuevas edificaciones casi en cada sede de partido judicial, al tiempo que acometer inversiones en inmuebles singulares para sede de los grandes órganos colegiados. Además, la renovación del mobiliario y del material informático de estas sedes judiciales, y por tanto la inversión en los mismos, ha ido pareja a la de los edificios.

No obstante, los últimos traspasos, como Aragón, Cantabria o Extremadura han tenido cierta ventaja en el terreno de los bienes materiales, ya que en 1998 el Estado central comenzó a renovar los medios materiales de la administración judicial en el territorio de las CC.AA. que todavía gestionaba. Además, desde 2004, con la implantación de la nueva Oficina Judicial, el Estado está instalando en estos territorios nuevos programas, material informático y de telecomunicaciones, mobiliario e incluso construyendo nuevos inmuebles para sedes judiciales. También los últimos traspasos incluyen las infraestructuras de videoconferencia y grabación para todas las salas de vistas, lo que en el caso de las CC.AA. que recibieron primero la competencia les supone un gasto adicional y no los afrontan todas como una prioridad.

Además, en la nueva Oficina Judicial destaca la importancia de la informática. El Ministerio de Justicia está eliminando el formato papel en los procesos judiciales y que las distintas instancias de cada Oficina Judicial se comuniquen entre ellas a través de la red informática. Para ello se han desarrollado aplicaciones informáticas que también se traspasan, lo que supone un ahorro para las CC.AA. Para las que ya ejercían la competencia, se firman acuerdos de colaboración con el Ministerio de Justicia para el traspaso de algunas aplicaciones clave, pero hay otros, como los de gestión procesal, que no se están traspasando a las CC. AA que han recibido la competencia antes de 2002. Para estas, lo importante es que sus aplicaciones sean compatibles, ya que a veces es necesario que las Oficinas Judiciales ubicadas en una Comunidad Autónoma puedan leer e intervenir en los expedientes que tramita una Oficina Judicial ubicada en otra. Hemos de señalar que el CGPJ es el encargado de otorgar la certificación de compatibilidad y califica de 1 a 3 la compatibilidad de los distintos programas de gestión procesal que desarrollan las CC.AA. y el Estado.

Las inversiones en nuevas tecnologías de todo tipo, software, hardware e infraestructuras, son una necesidad constante en la gestión de la administración judicial. A largo plazo, una Comunidad Autónoma debería hacer inversiones de este tipo, en cualquier caso, lo que exige colaboración entre CC.AA., Ministerio de Justicia y C.G.P.J. para estudiar necesidades, conseguir financiación y ahorrar costes mediante economías de escala.

Para acometer estos gastos, las CC.AA. han de seguir negociando una vez traspasada la competencia. Estas negociaciones son fundamentalmente bilaterales, a iniciativa autonómica, y no contemplan ampliaciones de traspaso de bienes materiales o de funciones. El resultado de estas negociaciones es la firma de convenios, negociados en las entre ambas partes en las Comisiones Bilaterales de Cooperación entre cada CC.AA. y el Estado central. Estos convenios de colaboración bilateral pueden cubrir, por ejemplo, la financiación del desarrollo e implantación de infraestructuras tecnológicas, hardware y software en la administración judicial, incluso para cable de banda ancha 
en las sedes judiciales. También pueden financiar también otros aspectos y compensar posibles errores en los cálculos del coste efectivo, aunque tradicionalmente los sectores que más favorecen estos convenios son la formación y las nuevas tecnologías.

No obstante, hay que considerar que estas Comisiones Bilaterales de Cooperación tratan asuntos generales de interés mutuo y se producen en el máximo nivel político, Ministro o Secretario de Estado por parte estatal y Consejero por parte autonómica, y en muchos casos no son los competentes específicos en materia de administración judicial, si no los encargados de presidencia o relaciones institucionales. Esto puede implicar que las inversiones en administración judicial se compensen con otras inversiones en otros campos, por lo que dependen en buena medida de la prioridad que el den los gobiernos autonómicos a esta materia.

En cualquier caso, es importante señalar que esta vía bilateral deja un margen a la discrecionalidad de las posibles inversiones del Estado central, que puede incrementar la asimetría en el ejercicio ordinario de la competencia entre unas comunidades y otras.

Esta simetría se garantiza más a través de las relaciones multilaterales entre el Estado y todas las CC.AA. que ejercen la competencia, a través de la Conferencia Sectorial en materia de administración judicial. En esta Conferencia Sectorial participan, por parte del Estado central el Ministro o el Secretario de Estado de Justicia y por parte autonómica los consejeros que se encargan de la materia en el caso de que esté traspasada. La Conferencia Sectorial sirve para coordinar las políticas de administración judicial, por ejemplo, respecto al personal, los sistemas informáticos, la implantación de la Oficina Judicial o la mejora de la financiación del conjunto de las CC.AA.

Sin embargo, para el Estado central esta Conferencia Sectorial no es un órgano siempre amistoso. Esto se debe a que desde 1999 existe un foro en el que las CC.AA. que ejercen la competencia coordinan sus posiciones, buscando estrategias y posicionamientos comunes frente al Estado central en la Conferencia Sectorial. La Comisión de Coordinación de las CC.AA. con competencias en materia de Administración judicial nació para posicionarse frente al Pacto de la Justicia que se negociaba entonces, pero posteriormente ha evolucionado para tratar cuestiones de financiación, intercambiar experiencias o cuestiones de interés común, como son las reivindicaciones del personal autonómico al servicio de la administración judicial, que son cuerpos especiales que no se integran en el conjunto de la administración autonómica y suelen plantear demandas específicas a las CC.AA.

No obstante, la administración judicial no suele aparecer como una competencia especialmente conflictiva entre el Estado y las CC.AA. en los medios de comunicación. En buena medida se debe a que no es prioritaria para los gobiernos autonómicos, que prefieren dar la batalla en otras competencias. Técnicos de las administraciones de Canarias, Navarra, la Comunidad Valenciana y del propio Ministerio de Justicia han señalado que la administración judicial es una competencia que, si funciona bien, no tiene un claro beneficio político, dado que la percepción ciudadana atribuye el rendimiento a otras instancias, como al Juez o al Poder Judicial. No es como el caso de las carreteras o la vivienda, cuyas mejoras se perciben directamente por los ciudadanos. Esta falta de réditos políticos hace que los líderes políticos de las CC.AA. no siempre consideren interesante una apuesta por la mejora de la prestación de servicios en esta materia.

Como se ha podido apreciar la Administración judicial es una competencia subfinanciada, sobre todo en las CC.AA. que la recibieron en los primeros años y no disponen de un sistema de financiación especial como País Vasco y Navarra. Los esfuerzos políticos por conseguir financiaciones adicionales del Estado central, por 
ejemplo, para infraestructuras de sedes judiciales o informatización, suponen que esos fondos no se ocupen en infraestructuras más rentables políticamente. Así, en situaciones de reducción del gasto, la administración judicial entra en el punto de mira de los "recortes" de los gobiernos autonómicos.

No obstante, si analizamos el conjunto de la información recopilada podemos identificar un path dependence diferente en cada comunidad autónoma, que comienza en el acuerdo inicial del traspaso, que hemos visto que es diferente y bilateral para cada una. Aunque la subfinanciación sea común, no llega a tener el mismo grado porque el Estado central no ha tratado a todas las comunidades por igual en el momento del traspaso. Influye el momento histórico en el que se negocia, la relación entre los partidos gobernantes en los gobiernos autonómico y estatal en ese momento, el nivel de información sobre los costes reales de la prestación de los servicios que tengan las administraciones respectivas y el estado en el que se traspasan los medios materiales y particularmente los edificios.

Los traspasos producidos antes de 1996 a las comunidades con un régimen de financiación general, durante los mandatos de Felipe González, son los más ventajosos. Primero Cataluña en 1990 y después Galicia, en 1994, consiguieron notables ventajas en sus acuerdos que compensaron en buena medida unos cálculos de coste iniciales que eran muy difíciles de realizar por falta de información y que eran defectuosos. Las relaciones de los gobiernos de Felipe González con el gobierno catalán en 1990 no eran malas en aquel momento y tampoco se pude decir que fueran especialmente conflictivas con el gobierno de Fraga en Galicia en 1994 si consultamos la hemeroteca, a pesar de que si lo fueran con su partido a nivel estatal. En última instancia, el gobierno central en 1994 estaba en una posición de minoría en el parlamento, lo que lo hacía más débil. Por este motivo, se generó en aquella época un rumbo de decisiones respecto a esta competencia en Cataluña que implicó el pago de las nuevas sedes judiciales de forma automática por parte del Estado central y que generó un marco de relaciones intergubernamentales bilateral, al margen del resto de comunidades, en materia de administración de justicia. En el caso gallego también se generó un rumbo de decisiones con un marco de relaciones diferente, bilateral, para esta materia, en el que existen unas compensaciones económicas que son específicas para esta Comunidad. En ambos casos se generan unos intereses particulares en estas comunidades, que dificultan que los puedan compartir con el resto de los que ejercen la competencia, y que ilustra mucho sobre la letra pequeña del estado autonómico y de cómo se han favorecido las relaciones bilaterales sobre las multilaterales entre los gobiernos en el caso español.

Las comunidades autónomas que recibieron la competencia entre 1996 y 2000 han tenido bastantes más problemas en las negociaciones. A pesar de que el Estado central contara con más información sobre los costes de la competencia en cada territorio, estos no se ajustaron, y hubo errores hasta en el traspaso del personal. Las relaciones entre el gobierno central con los gobiernos autonómicos de Andalucía, Canarias y Valencia eran diferentes, siendo peores en el caso andaluz, gobernado por el partido principal de la oposición a nivel estatal, intermedias en el canario, gobernado por Coalición Canaria junto al propio partido de gobierno a nivel estatal, y buenas con el gobierno valenciano, con mayoría absoluta del mismo partido. Así, los errores fueron sustancialmente mayores en el caso andaluz, que recibió las competencias tanto en bienes materiales como en personal con un claro déficit para prestar el servicio. Cada una de estas comunidades también ha tenido 
su propio rumbo de decisiones, orientado en este caso a disponer fondos propios para sufragar los déficits de prestación, y a buscar compensaciones económicas del Estado central en otras materias o en financiaciones especiales. Estas comunidades han estado interesadas en que se hubieran potenciado más una relación multilateral entre las CC.AA. y el Estado central, y suelen buscar más coordinación en las reivindicaciones, sin dejar la vía bilateral, pero dejando esta para negociaciones más generales sobre financiación autonómica, no tanto en relaciones bilaterales en materia de administración de justicia.

Por último, tenemos las comunidades que reciben sus competencias desde 2001, con el acuerdo de modernización de la administración de justicia, que han tenido traspasos con un mayor nivel de información, menos desajustes en los costes reales del servicio y a medida que ha avanzado el tiempo, con mejor situación de las infraestructuras traspasadas. En estos casos, las negociaciones y los traspasos han sido más transparentes y los rumbos posteriores de decisiones y relaciones intergubernamentales posteriores también. En estos casos, aunque también hay subfinanciación debido a que el servicio es más relevante de lo que históricamente se ha considerado y requiere de más medios de forma general, lo cierto es que son traspasos más homogéneos. En estos casos, aunque puedan requerir financiaciones adicionales, favorecen que sea en marcos multilaterales, que se defiendan intereses comunes y que se financien programas para todas las CC.AA., y que si se realizan financiaciones adicionales sea por motivos objetivos, como tener que financiar sedes de órganos centrales.

Hay que tener en cuenta que la administración judicial es cada vez más importante para los ciudadanos, sobre todo en momentos en los que se incrementa la conflictividad social. Además, el retraso en la resolución de los casos en las jurisdicciones contencioso-administrativa y mercantil crea problemas de planificación económica, liquidez y obtención de créditos para las empresas. Estos problemas son especialmente importantes para las pymes, a las que además el gasto en asesoría legal les supone una carga proporcionalmente superior a las grandes empresas, y esta carga es mayor cuanto más tiempo se retrasa la resolución de los asuntos.

\section{Principales hallazgos y conclusiones}

La pretensión inicial de la investigación era conocer si existen procesos de traspasos mejores y peores para las comunidades autónomas. En el caso de la administración de la administración de justicia la respuesta es afirmativa. El caso catalán, y en segundo nivel el gallego, podemos considerarlos como procesos más ventajosos desde el punto de vista autonómico, excluyendo los casos vasco y navarro, ya que sus sistemas de financiación hacen que los procesos no sean referencias. Los acuerdos de financiación adicional que lograron esas comunidades son una aspiración inalcanzable para el resto de CC.AA.

Pero la información hallada en la investigación, analizado desde un punto de vista más general, nos revela aspectos concretos del funcionamiento del Estado autonómico, la letra pequeña de cómo se ha desarrollado su construcción, más allá de los preceptos constitucionales. Así, el traspaso de la administración judicial a las CC.AA. nos enseña que el Estado autonómico se ha conformado de forma asimétrica, y las consecuencias para el posterior funcionamiento ordinario, que tiende a una bilateralidad que premia 
discrecionalmente a unas CC.AA. o a otras, tanto por razones de relaciones entre partidos, como porque en el momento de realizar el traspaso no había información suficiente. Esta asimetría no estaba prevista y no ha sido reflejada por los estudiosos de la materia (Fossas y Requejo, 1999; Aja, 2001, Cuevas, 2013) porque está en la letra pequeña del funcionamiento del Estado. Las asimetrías que se señalan suelen ser de carácter cultural y su reflejo constitucional, y las de carácter fiscal.

En suma, el caso del traspaso de esta competencia a las CC.AA., que se ha producido a lo largo de cerca de 30 años, nos desvela que el momento en el que se realiza el traspaso de una competencia ha determinado cómo se hace, los intereses que tendrán las partes en el futuro, y por tanto cómo ejercerá la Comunidad la competencia, en cuanto a medios disponibles, y cuáles serán las relaciones con el Estado central en esta materia, generando por tanto un rumbo para cada comunidad, un path dependence, que marca asimetrías. No obstante, estos rumbos no tienen por qué ser eternos, pueden surgir nuevas ventanas de oportunidad en un futuro, tanto en el aspecto financiero de la competencia como en el de una mayor transparencia y simetría en las relaciones intergubernamentales en un posible reajuste del Estado autonómico.

\section{Documentos}

- Comisión de Coordinación de las CC.AA. Con competencias en materia de Administración Judicial (1999). “Acuerdo de Constitución”. En: http://www. gobcan.es/dgjusticia/Gestion/biblioteca/Documentos/Documentos.Comision\%20Coordinacion.htm (Consultado, el 12 de abril de 2018).

- Ley Orgánica 19/2003, de 23 de diciembre, de modificación de la Ley Orgánica 6/1985, de 1 de julio, del Poder Judicial.

- Ley 21/2001, de 27 de diciembre, por la que se regulan las medidas fiscales y administrativas del nuevo sistema de financiación de las Comunidades Autónomas de régimen común y ciudades con Estatuto de Autonomía.

- Ley 38/1988, de 28 de diciembre, de Demarcación y Planta Judicial. Resolución de 20 de noviembre de 1995 sobre la aprobación del "Acuerdo del Consejo de Política Fiscal y Financiera de 1/1995, de 15 de marzo, de modificación del método para el cálculo del coste de los servicios transferidos a las Comunidades Autónomas".

- Sentencia Tribunal Constitucional, 108/1986, de 29 de julio.

- Sentencia Tribunal Constitucional, 56/1990, de 29 de marzo.

- Sentencia Tribunal Constitucional, 62/1990, de 30 de marzo.

- Sentencia Tribunal Constitucional, 105/2000, de 13 de abril.

\section{Bibliografía}

Astarloa Huarte-Mendicoa, I. (2016). "La reforma del Reglamento del Congreso y el procedimiento legislativo", en El Cronista del Estado Social y Democrático de Derecho, $\mathrm{n}^{\mathrm{0}} 58$, pp. 24-30.

Ballesteros, M. C. R. (2007). "La nueva oficina judicial para el siglo XXI”, en Anuario Jurídico y Económico Escurialense, nº 40, pp. 303-322. 
Bedoya, M. R. (2009). Las potencialidades del institucionalismo histórico centrado en los actores para el análisis de la política pública. Contingentes de trabajadores extranjeros en España. Estudios políticos.

Boudon, R. (2009). "Rational choice theory”, en Social Theory, no 179, pp. 33-68.

De Buján, A. F. (2009). "El necesario debate sobre el nuevo modelo de Oficina Judicial” en Diario la Ley, Sección Tribunal, nº 7919, junio.

Carrillo, F. J. G. (2005). "El secretario judicial, clave en el nuevo modelo de oficina judicial tecnológicamente avanzada", en Revista de la Facultad de Derecho de la Universidad de Granada, no 8 , pp. 85-107.

Cendón, A. B. (2004). "El gobierno en la Constitución y en la ley del gobierno de 1997: ¿Colegialidad o presidencialismo?”, en Teoría y Realidad Constitucional, n 14, pp. 6486.

Consejería de Justicia y Administración Pública (2003). La justicia en Andalucía. Cinco años de gestión autonómica: 1997-2002. Sevilla Junta de Andalucía.

Dalmau, R. M. (1999). Aspectos constitucionales del ministerio fiscal. Valencia: Universitat de València.

García De La Cruz, J. J. (2003). "Plazos medios de finalización en los Tribunales Contencioso-administrativos ubicados en la Comunidad de Madrid: realidad versus expectativas de los usuarios", en Revista Jurídica de la Comunidad de Madrid, n 15, pp. 179-200.

García Morillo, J. (1998). La democracia en España. Madrid, Alianza Editorial.

Gimeno Sendra, V. (2010). Introducción al derecho procesal. Madrid: Colex.

Gibson, C. C., Mckean, M. A., \& Ostrom, E. (EDS.). (2000). People and forests: Communities, institutions, and governance. London, Mit Press.

Gimeno Sendra, V. (2010). "La prueba preconstituida de la policía judicial”, en Revista Catalana de Seguretat Pública, n 22, pp. 34-67.

Gobierno de La Nación, Partido Popular, Partido Socialista Obrero Español. (2001). Principios del pacto de Estado para la reforma de la Justicia. En: http://www.gobcan.es/dgjusticia/Gestion/biblioteca/Documentos/Documentos.Pacto\%20de\%20Estadol.htm (Consultado, el 7 de abril de 2018).

Gómez, M. M., \& Serrano, N. G. C. (2015). La reforma de la Ley de Enjuiciamiento Criminal en 2015. Madrid: Ediciones Jurídicas Castillo de Luna.

Hall, P. A., \& Taylor, R. C. (1996). "Political science and the three new institutionalisms", en Political Studies, vol. 44, no 5, pp. 936-957.

Jellinek, G. (1910). Teoría General del Estado. México: Fondo Económico.

Jiménez Asensio, R. (1999). "Un problema mal resuelto: la gestión del personal al servicio de la administración de la justicia en el estado autonómico", en Revista Vasca de Administración Pública, ${ }^{\circ}$ 53, enero-abril, pp. 91-115.

- (1998). Dos estudios sobre administración judicial y comunidades autónomas. Madrid: Instituto Vasco de Administración Pública-Civitas.

Kelsen, H. (1934). Teoría pura del Derecho. Madrid: Trotta.

Lenski, G. E. (2013). Power and privilege: A theory of social stratification. London: UNC Press Books.

March, J. G., \& Olsen, J. P. (2010). Rediscovering institutions. London: Simon and Schuster. Ministerio de Justicia. (2005). La nueva oficina judicial. Madrid: Ed. Ministerio de Justicia.

- (2005). Plan del Ministerio de Justicia para la implantación de la Nueva Oficina Judicial en su ámbito de competencias. Madrid: Ed. Ministerio de Justicia.

Morato, M. M. (2005). "El nuevo modelo de oficina judicial”, en Revista Jurídica de Castilla y León, $\mathrm{n}^{\mathrm{o}}$ 5, pp. 173-190. 
Moreno Catena, V. (2002). "El papel del Ministerio Fiscal en el Estado Democrático de Derecho", en Cuadernos de Derecho Público, n 16, pp. 139-166.

Nieto, A. (2005). El desgobierno judicial. Madrid, Editorial Trotta.

North, D. C. (1991). "Institutions". Journal of Economic Perspectives, vol. 5, nº 1, pp. 97 112.

Orero, F. C. (2010). "De la antigua secretaría a la nueva oficina judicial", en Boletín del Ministerio de Justicia, vol. 64, n 2104, pp. 468-482.

Pastor Prieto, S. (2003). "Eficacia y eficiencia de la justicia”, en Papeles de Economía Española, $\mathrm{n}^{\mathrm{o}}$ 95, pp. 272-305.

Pastor Prieto, S y Rosales López, V. (2005). "Dos dimensiones de la eficiencia de la justicia", en Economistas, n 105 , julio, pp.103-114.

Pérez Royo, J. (2016). Curso de Derecho Constitucional. Madrid: Marcial Pons.

Peters, B. G. (2003). “La capacidad para gobernar: ¿retrocediendo hacia el centro?”. Revista del CLAD reforma y democracia, 27, 7-28.

Ruíz Risueño, F. (2012). El proceso contencioso-administrativo. Madrid: Ed. Colex.

Salgado, C. A. (2010). "Comentarios a la Ley de Enjuiciamiento Civil”, en InDret: Revista para el Análisis del Derecho, n 1, pp. 2-26.

Samuels, W. J. (1995). “The present state of institutional economics", en Cambridge Journal of Economics, vol. 19, n 4, pp. 569-590.

Santaolalla López, F. (2013). Derecho parlamentario español. Madrid: Librería-Editorial Dykinson

Stone, C. N. (2006). "Power, reform, and urban regime analysis", en City \& Community, vol. $5, \mathrm{n}^{\mathrm{o}} 1$, pp. 23-38.

Tsebelis, G. (1990). Nested games: Rational choice in comparative politics. California: Univerty of California Press.

VV.AA. (2001). La reforma de la justicia. Madrid: Fundación Encuentro. 
